\title{
A New Species of Genus Anelpistina and the Second Described Nicoletiid (Zygentoma: Insecta) Species from the Mayan Ruins of Palenque, Chiapas, Mexico
}

\author{
Luis Espinasa, Emily Collins, and Kimberly Socci \\ School of Science, Marist College, 3399 North Road, Poughkeepsie, NY 12601, USA \\ Correspondence should be addressed to Luis Espinasa, luis.espinasa@marist.edu
}

Received 30 September 2012; Accepted 12 November 2012

Academic Editors: B. Crother, C. L. Frank, and V. Ketmaier

Copyright ( 2012 Luis Espinasa et al. This is an open access article distributed under the Creative Commons Attribution License, which permits unrestricted use, distribution, and reproduction in any medium, provided the original work is properly cited.

\begin{abstract}
Recent studies on the American nicoletiid insects ("silverfish") of the subfamily Cubacubaninae have shown that the group is more species rich than previously recognized. It has become common to find that a single locality is inhabited by more than one species of nicoletiid. In previous studies, a species from genus Squamigera had been described from the rainforest surrounding the Mayan ruins of Palenque, Chiapas, Mexico. We report here the presence of two more species of nicoletiids in the same locality and we describe here a new species of genus Anelpistina. DNA sequence data and morphology are provided to differentiate these species.
\end{abstract}

\section{Introduction}

Insects of the nicoletiid subfamily Cubacubaninae are frequently encountered under rocks and in the caves of Mexico and Central America but are generally understudied. Many species remain to be described. The state of Chiapas within Mexico, with its great environmental diversity, would appear to be a place particularly in a need of more studies. A few species have been described: Anelpistina yatbalami [1], from the Mayan ruins of Yaxchilan; Anelpistina nandalumii [2], from the Sumidero Canyon; Squamigera cumcalcaris [3], from "Grotta I Finca S. Anita" cave near Simojovel de Allende; Squamigera sp. [3], from Grutas del Chorreadero, near Chiapa de Corzo; and, finally, Squamigera pakali [4], from the Mayan ruins of Palenque.

The ancient ruins of Palenque, Chiapas, Mexico, have been the site of two collecting field trips. As a result of extensive searching for specimens under rocks, a total of seven nicoletiid specimens were secured. Five belonged to the previously mentioned $S$. pakali and two belonged to two species of genus Anelpistina. In this paper we describe a new species of Anelpistina and we report its 16S rRNA sequence.

\section{Materials and Methods}

2.1. Morphology. The specimens were found under rocks in the rainforest surrounding the Mayan ruins of Palenque, Chiapas, Mexico. Specimens were collected by hand and deposited in $100 \%$ ethanol. Dissections were made with a Motic K series stereo microscope and the different body parts were mounted in fixed preparations with Cytoseal 60 solution (Richard-Allan Scientific). Illustrations were made with the aid of a camera lucida attached to a compound microscope.

2.2. Molecular Data. Genomic DNA was extracted using Qiagen's DNeasy Tissue Kit by digesting a leg in lysis buffer of the holotype. Amplification and sequencing of the $16 \mathrm{~S}$ fragment were done as in [1], following standard protocols and primers used in the past for nicoletiids. Chromatograms obtained from the automated sequencer were read and contigs were made using the sequence editing software SequencherTM 3.0. External primers were excluded from the analyses. The program ClustalW was used to obtain a neighbor-joining tree, which includes all nicoletiid species for which the $16 \mathrm{~S}$ has been sequenced. 


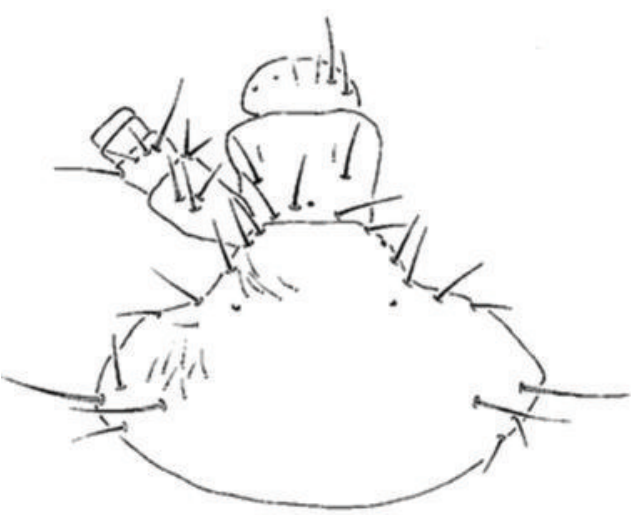

(a)

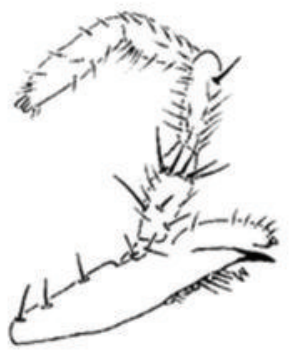

(c)


(g)

(d)

(h)

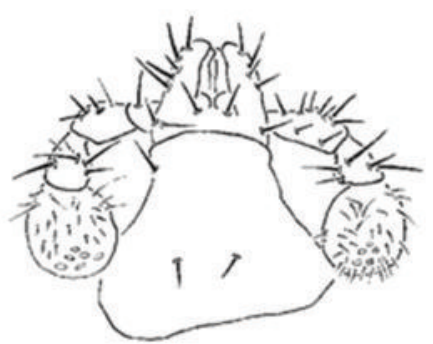

(b)

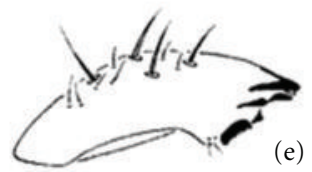

(e)
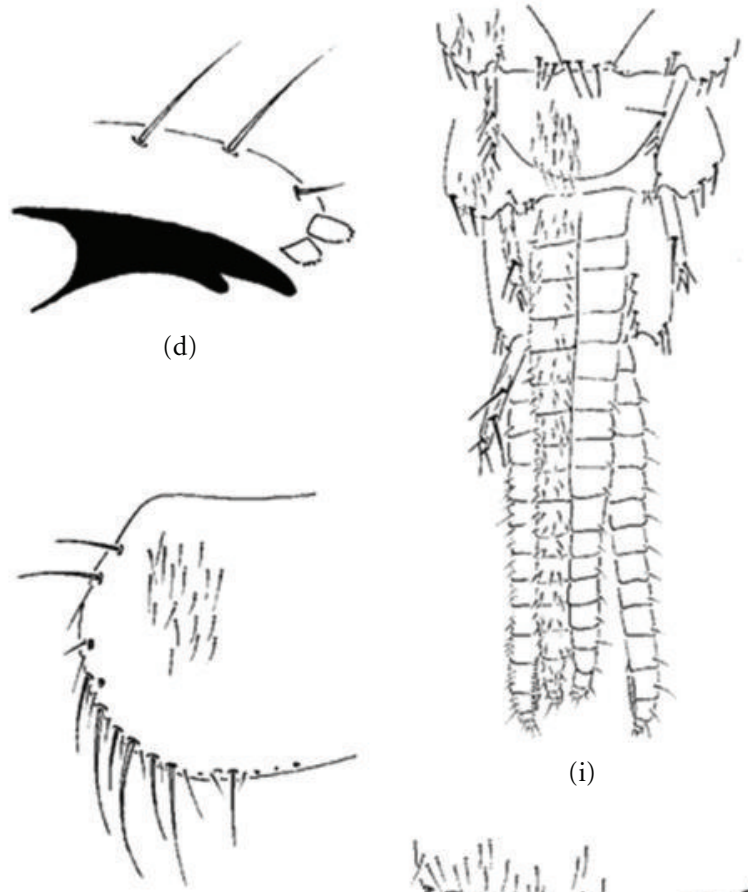

(i)

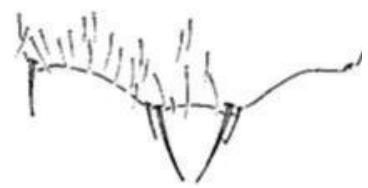

(j)

Figure 1: Anelpistina muwaanmati n. sp.: microchaetae partially shown. (a) head; (b) labium; (c) maxilla; (d) apex of maxilla; (e) mandible; (f) hind Legs; (g) claws; (h) mesonotum; (i) genital area; (j) uroterguite X. Scale bar in bottom right equals $0.2 \mathrm{~mm}$ for (a)-(c), (e)-(f), (h), and (j). For (d) and (g) scale bar equals $0.05 \mathrm{~mm}$ and for (i) equals $0.25 \mathrm{~mm}$.

\section{Results}

3.1. Morphology. Anelpistina muwaanmati, Espinasa, Collins and Socci new species (Figures 1(a)-1(j)).

3.2. Type Material. Under rocks in the nearby jungle by the side of one of the creeks of Palenque ruins, Chiapas,

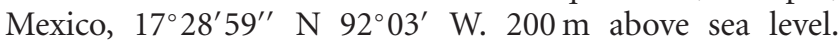
Female holotype $(5.7 \mathrm{~mm}) .7 / 21 / 11$. Espinasa L., Espinasa R., and Espinasa J. cols. Holotype will be deposited in the collection of the American Museum of Natural History, New York.

3.3. Description. Maximum body length $5.7 \mathrm{~mm}$. Maximum conserved length of antennae $3 \mathrm{~mm}$ and of caudal appendages $2 \mathrm{~mm}$. General color light yellow to white. Antennae of females as shown in Figure 1(a). Pedicellus less than half as long as basal article. No adult males were available for study, but it is expected that the pedicellus could 
be longer and with the unicellular glands as is typical in the genus. Head with approximately $5+5$ macrochaetae on border of insertion of antennae (Figure 1(a)). Mouthpart appendages relatively short. Labial palp as in Figure 1(b). Apical article's width equal to its length and longer than penultimate article. Penultimate article with bulge containing macrochaetae. Labium and first article of labial palp with macrochaetae. Maxilla as shown in Figure 1(c). Last article about one-third longer than penultimate. Apex of maxillary palp with two conules of similar width (Figure $1(\mathrm{~d})$ ). Two teeth on lacinia. Mandibles chaetotaxy as in Figure 1(e), with 4 macrochaetae.

Legs relatively short and stout. Tibia on 3rd leg approximately $3.5 \mathrm{X}$ longer than wide and subequal to tarsus (Figure 1(f)). Claws of normal length and with a hairy appearance (Figure $1(\mathrm{~g})$ ), as seen in [1].

Thoracic nota with many macrochaetae on lateral borders apart from several setae of varied sizes (Figure 1(h)). Abdominal sterna I entire, sterna II-VII subdivided into coxites and sternites, as in other members of subfamily. It is currently unknown if urosterna III and IV of males have modification, as no males were available. Stylets IX bigger than the others, with two macrochaetae and an extra subapical pair. Other stylets have only one macrochaetae plus the subapical pair (Figure 1(i)).

Subgenital plate of female is rounded (Figure 1(i)). Ovipositor surpassing apex of stylets IX by slightly more than one and a half the length of stylets (Figure 1(i)). Gonapophyses with approximately 19 articles. Genital area of the male unknown.

Uroterguite $\mathrm{X}$ posterior angles with two long macrochaetae and two setae of smaller size (Figure $1(j)$ ). Female caudal appendages without spines. It is likely that adult males will develop spines, as in other members of the genus.

\section{Known Range}

It is known only from the type locality.

\section{Etymology}

The name muwaanmati is derived from "Muwaan Mat," a mythological figure of Palenque, born seven years prior to the "zero date" of the Maya creation in 3121 BC. She is the mother of Palenque's trio of patron gods and also accedes with the title "Divine Lord of Matwiil," becoming an allegory for the founding dynasty of the Palenque kings. Previous nicoletiid species discovered in Mayan ruins have been named after their male kings. Since this species is described with a female, it seems only fitting to use the name of one of the most important queens in ancient Maya culture.

\section{Molecular Data}

The 16S rRNA fragment with primers excluded is as follows (GenBank number KC152460):
5'GGTCCCACGAATYTGGTTTGTGGGATTTGGCCTGCCCAATGATTTATATTGAATGGCCGCGGTATTTTGACCGTGCAAAGGTAGCATAATCATTAGTCTCTTAATTAGGGTCTGGAATGAAGGGCTGGACAAGGGGGGCTCTGTCTTAGATTAATACGTTTGAATTTTACTTTTGAGTGAAAAGGCTTAAATTTTCTTGGGGGACGATAAGACCCTATAGAGCTTTATTCCTAACTGCTAGGGCTAGTAGTAGGGGATTTTGTTGGGGTGACGGGGAGATACATGTAACTCTCCTTTGTAGGGATTATTTATTAATATGAGTTGTGATCCATTAGGTTTGATAGAAGGATTAAGTTACCTTAGGGATAACAGCGTAATCCCCTTTGAGAGTTCATATCGACAAGGGGGATTGCGACCTCGATGTTGGATTAAGGAGTTTTAGTGGTGGAGAGGCTACTAAGGAGGGTCTGTTCGACCCTTAAATCTTTACA3'.

While there is no "magical number" by which to determine how much DNA sequence difference is needed to make two populations belong to the same or different species, comparison with other species can be informative. Using the 16S rRNA fragment sequences of nicoletiid species across the subfamily Cubacubaninae [5], it can be observed that pairs of specimens within a population differ by an average of 1.7 nucleotides (range $0-7 ; n=29$ ), by 3.4 nucleotides (range $0-13 ; n=22$ ) in different populations of the same species, and by 31.2 nucleotides (range $10-64 ; n=$ 14) among sister species. The Palenque specimen has more than 70 mismatches when compared to any other species of Cubacubaninae whose $16 \mathrm{~S}$ has been sequenced. A neighbor joining tree shows it is basal to all of the major groups of Anelpistina [1], therefore, supporting that it belongs to a previously undescribed species.

\section{Discussion}

Three different species of Cubacubaninae have been found at the same locality of the Mayan ruins of Palenque: Squamigera pakali, Anelpistina muwaanmati n. sp., and an undescribed species of Anelpistina. The Squamigera and the Anelpistina can easily be differentiated because Squamigera has scales over its body, while the Anelpistina lacks them. We have not made an effort to describe the second Anelpistina because only a juvenile female whose morphology has not developed to a stage adequate for complete comparisons is available. Nonetheless, A. muwaanmati and A. sp. can be differentiated because the first species has 4 macrochaetae on the mandible and head with approximately $5+5$ macrochaetae on border of insertion of antennae. The undescribed species has many more setae on both structures.

Anelpistina muwaanmati n. sp. can be differentiated from most other species of Anelpistina by a unique combination of characteristics seen in Table 1 of [6]: Galea with conules of similar size, head with about five macrochaetae by insertion of antennae, and mandible with four macrochaetae. There are six described species that share this combination: from the Peruvian species A. weyrauchi [7] and A. ariasea [8] the new species is easily distinguished from them because the former has longer ovipositors and it has claws with small teeth. From the Cuban A. negreai [9] and A. ramosi [7] and the Mexican A. mexicana [10], the new species 
is easily distinguished because it has more macrochaetae in the stylets and its ovipositors are shorter. Finally, from the Aruban species, A. arubana [11], the new species is easily distinguished because in the uroterguite $X$, instead of the long and shallow posterior emargination found in the new species, the emargination is very short and the distance between the macrochaetae is only $1 / 4-1 / 5$ th the length of the macrochaetae. Unique only to the new species is also that the posterior angles of uroterguite $\mathrm{X}$ have two long macrochaetae and two setae of smaller size, which is somewhat more similar to Nicoletia phytophila, than to the norm of Anelpistina, which is to have more setae of subequal sizes.

\section{Conflict of Interests}

The authors of the paper do not have a direct financial relation with the commercial identities mentioned in this paper that might lead to a conflict of interests for any of the authors.

\section{Acknowledgments}

The authors thank Amy Cahill, Sean McCaffery, Ramon Espinasa, and Jordi Espinasa for their collaboration in the field colleting expedition. Mary Botelho helped with the illustrations. A VPAA Grant from Marist College supported the travel expenses for LE and the School of Science supported KS expenses. Molecular work was done with the help of the students of the Genetics Course (BIO320) of fall 2011 at Marist College.

\section{References}

[1] L. Espinasa, C. Flick, and G. Giribet, "Phylogeny of the American silverfish Cubacubaninae (Hexapoda: Zygentoma: Nicoletiidae): a combined approach using morphology and five molecular loci," Cladistics, vol. 23, no. 1, pp. 22-40, 2007.

[2] L. Espinasa, K. Socci, S. McCaffery, and A. Cahill, "A new species of Anelpistina (nicoletiidae: zygentoma) from sumidero canyon national park, in Chiapas, Mexico," Proceedings of the Entomological Society of Washington, vol. 114, no. 3, pp. 285-292, 2012.

[3] L. Espinasa and B. Burnham, "Revision of the genus Squamigera (Insecta: Zygentoma: Nicoletiidae) with descriptions of two new species," Proceedings of the Biological Society of Washington, vol. 117, no. 4, pp. 582-593, 2004.

[4] L. Espinasa, M. Botelho, and K. Socci, "A new species of genus squamigera (Insecta: Zygentoma: Nicoletiidae) fromthe Mayan ruins of Palenque, Chiapas, Mexico," Journal of Entomology and Nematology. In press.

[5] L. Espinasa and G. Giribet, "Living in the dark-species delimitation based on combined molecular and morphological evidence in the nicoletiid genus Texoreddellia Wygodzinsky, 1973 (Hexapoda: Zygentoma: Nicoletiidae)," in Texas and Mexico. Memorial Museum Speleological Monographs, vol. 7 of Studies on the Cave and Endogean Fauna of North America, pp. 87-110, 2009.

[6] L. Espinasa and Y. Boyko, "A new troglobitic species of Anelpistina (Hexapoda: Zygentoma: Nicoletiidae) from northern Mexico," in Texas and Mexico Memorial Museum Speleological
Monographs, vol. 7 of Studies on the Cave and Endogean Fauna of North America, pp. 79-86, 2009.

[7] P. Wygodzinsky, "Contribution to the knowledge of the "Thysanura" and "Machilidae" (Insecta)," Revista Brasileira de Biologia, vol. 19, pp. 441-457, 1959.

[8] L. Espinasa, "A new species of the genus Anelpistina (Insecta: Zygentoma: Nicoletiidae) from Peru," Proceedings of the Biological Society of Washington, vol. 118, no. 2, pp. 337-343, 2005.

[9] P. Wygodzinsky and H. M. Hollinger, "A study of Nicoletiidae from Cuba (Thysanura)," Resultats des Expéditions Bioespeleologiques Cubano-Roumaines á Cuba, vol. 2, pp. 313-324, 1977.

[10] L. Espinasa, "Descripción de una nueva especie del genero Cubacubana (Zygentoma: Nicoletiidae) y registro del genero para América continental," Folia Entomológica Mexicana, vol. 82, pp. 5-16, 1991.

[11] L. F. Mendes, "Nouvelles données sur le Zygentoma (Insecta) de l'Amerique centrale et du Mexique," Bulletin du Muséum National d'Histoire Naturelle, Paris, vol. 8, no. 2, pp. 333-342, 1986. 

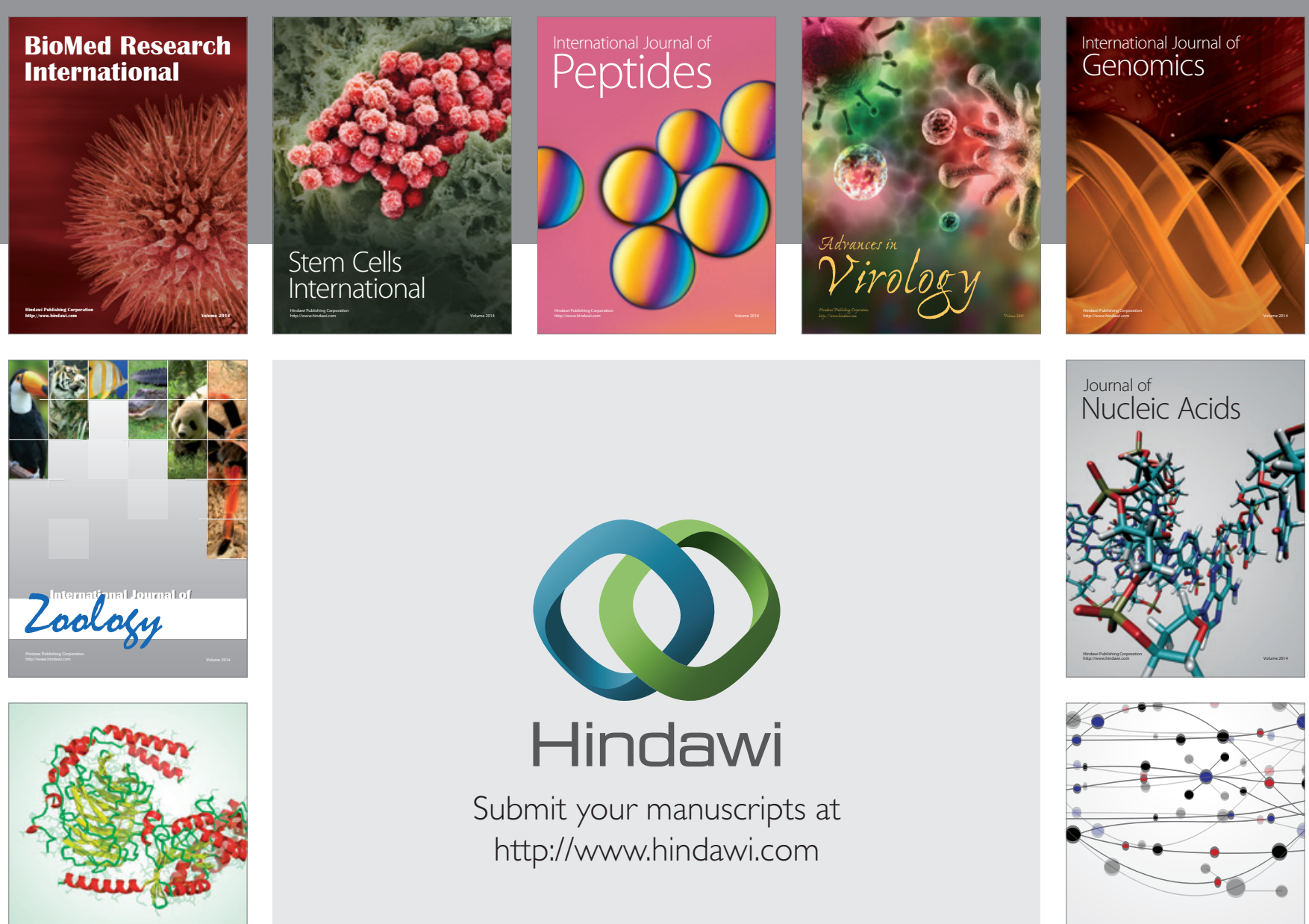

Submit your manuscripts at

http://www.hindawi.com

Signal ${ }^{\text {Jumal }}$ Transduction
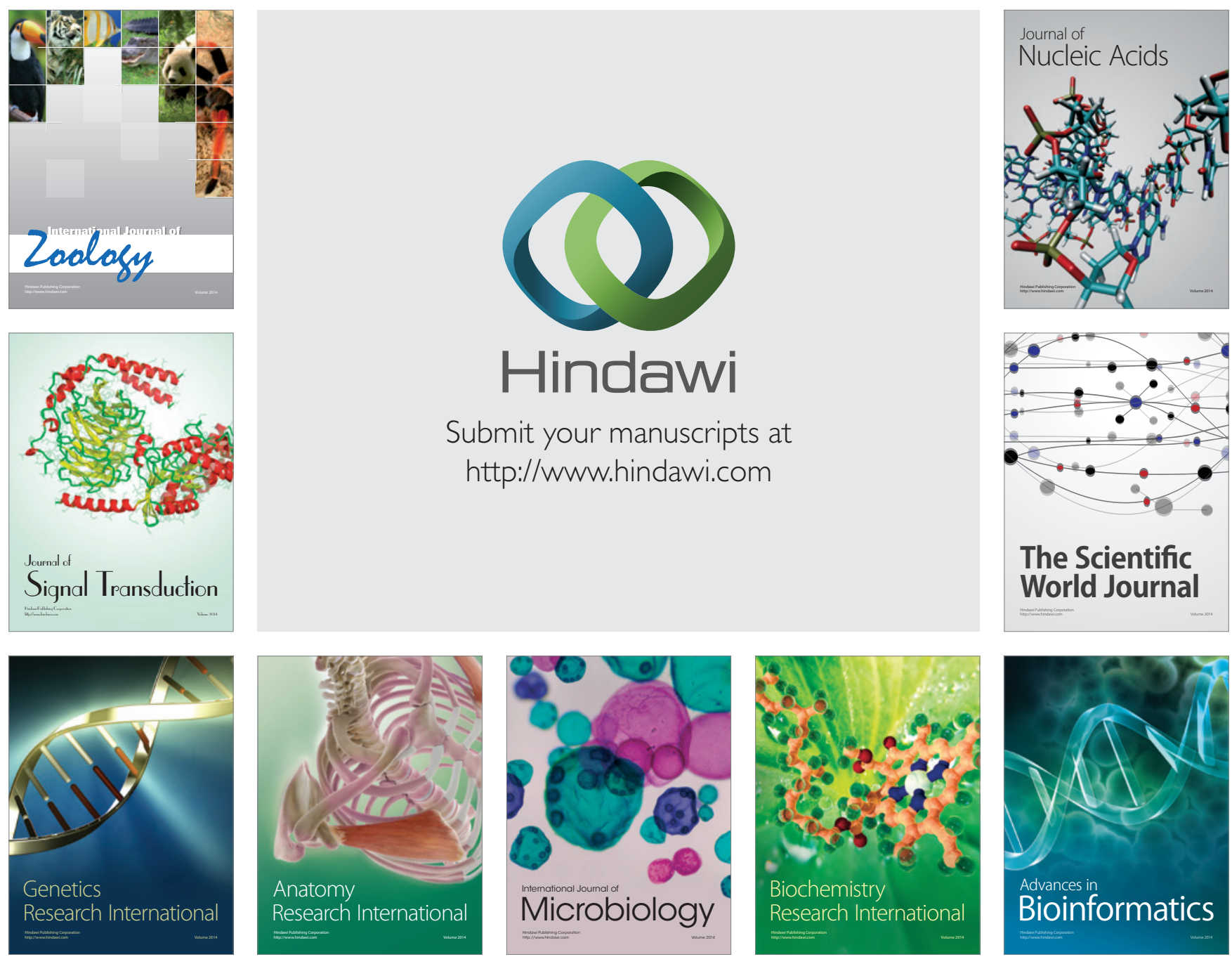

The Scientific World Journal
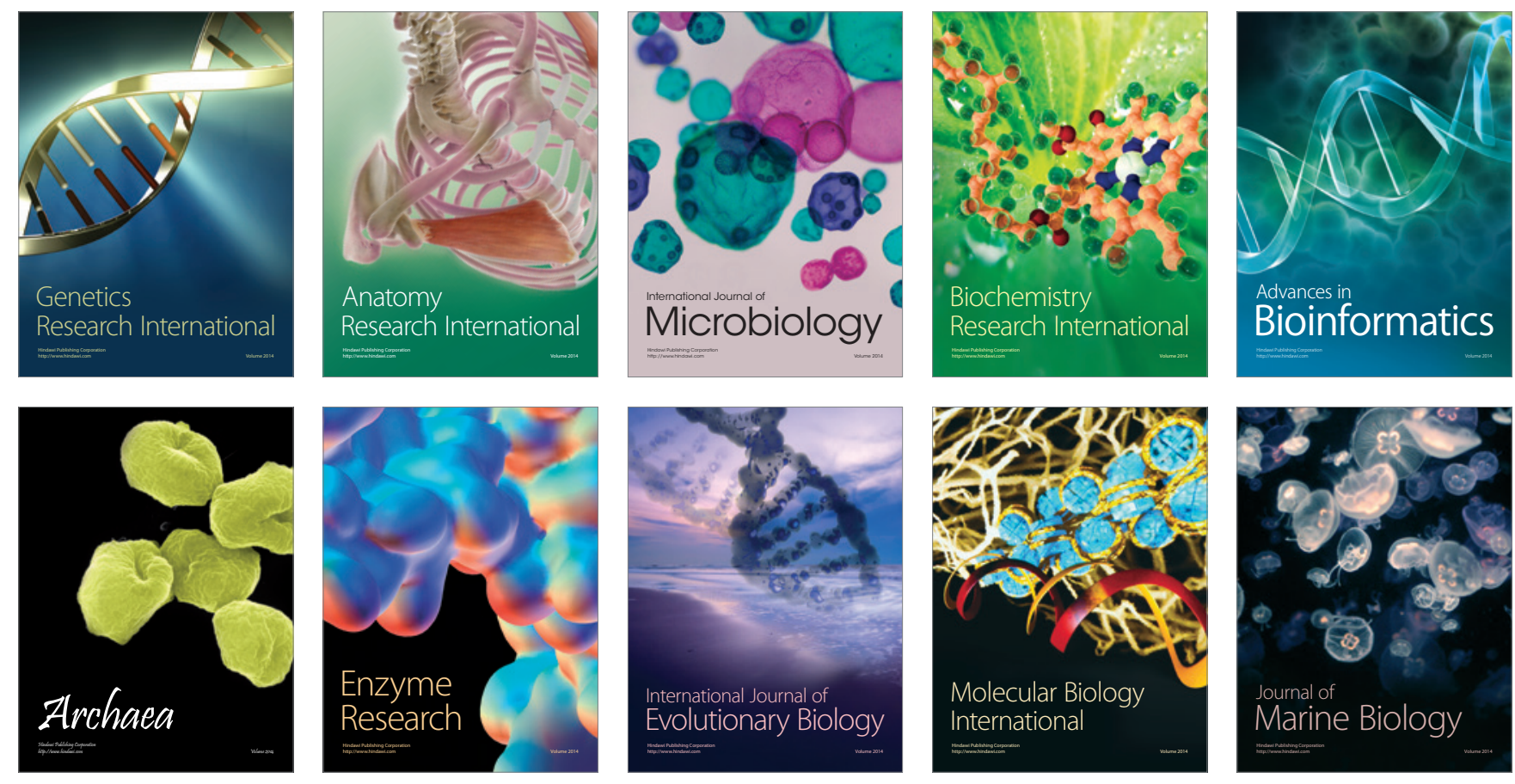